\title{
PRODUÇÃO DE ALFACE HIDROPÔNICA EM TRÊS AMBIENTES DE CULTIVO
}

\author{
EDÍLSON COSTA ${ }^{1}$, PAULO A. M. LEAL ${ }^{2}$
}

RESUMO: Propôs-se avaliar a produção hidropônica de alface-crespa, variedade "Vera", em bancadas inclinadas com canais de $100 \mathrm{~mm}$, utilizando a técnica de filme de solução nutritiva, em resposta à aplicação de dióxido de carbono e ao resfriamento evaporativo. Realizaram-se cinco ciclos de cultivo nos períodos de 20-3 a 17-4-2000 (C1); 25-5 a 29-6-2000 (C2); 13-7 a 21-8-2000 (C3); 27-8 a 2-10-2000 (C4) e 12-12-2000 a 10-1-2001 (C5). Avaliaram-se três casas de vegetação, sendo casa de vegetação sem sistema de resfriamento evaporativo do ar e sem injeção aérea de $\mathrm{CO}_{2}$ (A1); casa de vegetação com injeção aérea de $\mathrm{CO}_{2}$ e sem sistema de resfriamento evaporativo do ar (A2), e casa de vegetação com injeção aérea de $\mathrm{CO}_{2}$ e com sistema de resfriamento evaporativo do ar do tipo meio poroso-exaustor (A3). Avaliaram-se as massas frescas e secas em gramas, o número de folhas e a área foliar em $\mathrm{mm}^{2}$. Utilizou-se do delineamento inteiramente casualizado, em que, no ciclo $\mathrm{C} 1$, utilizaram-se 48 repetições por ambiente; para os ciclos $\mathrm{C} 2, \mathrm{C} 3$ e C5, foram 64 repetições, e para o ciclo $\mathrm{C} 4$, foram 24 repetições. $\mathrm{O}$ ambiente climatizado com incremento de dióxido de carbono promoveu melhor desenvolvimento das plantas, com maior número de folhas comercializáveis. Em ambientes não climatizados, o incremento de $\mathrm{CO}_{2}$ não resultou em aumento de produtividade da alface para a maioria dos ciclos. Em épocas de temperaturas mais elevadas, obtiveram-se plantas maiores, com maior número de folhas.

PALAVRAS-CHAVE: casa de vegetação, $\mathrm{CO}_{2}$, climatização.

\section{PRODUCTION OF HYDROPONIC LETTUCE IN THREE ENVIRONMENTS}

\begin{abstract}
It was proposed to evaluate the hydroponic lettuce production, variety "Vera", on inclined benches with channels of $100 \mathrm{~mm}$, and Nutrient Film Technique, as answer to carbon dioxide application and evaporative cooling. There were five cycles of cultivation from March, $20^{\text {th }}$ to April, $17^{\text {th }}(\mathrm{C} 1)$; from May, $25^{\text {th }}$ to June, $29^{\text {th }}(\mathrm{C} 2)$; from July, $13^{\text {th }}$ to August, $20^{\text {th }}(\mathrm{C} 3)$; from August, $27^{\text {th }}$ to October, $10^{\text {th }}(\mathrm{C} 4)$; from December, $12^{\text {th }}$ to January, $10^{\text {th }}(\mathrm{C} 5)$. In three greenhouses were tested the following systems: (A1) without evaporative cooling air $\mathrm{CO}_{2}$ aerial injection, (A2) with $\mathrm{CO}_{2}$ aerial injection and without evaporative cooling and (A3) with $\mathrm{CO}_{2}$ aerial injection and pad-fan evaporative cooling system. The fresh and dry mass of leaves in grams, number of leaves and leaf area in square millimeter were evaluated. The completely randomized statistical analysis was used. The cycle $\mathrm{C} 1$ were used 48 replications, for cycles C2, C3 and C5 were used 64 replications and $\mathrm{C} 5$ were used 24 replications. The results showed that greenhouse with evaporative cooling system and $\mathrm{CO}_{2}$ allow better development and greater lettuce yield. It was possible to conclude that the aerial injection of $\mathrm{CO}_{2}$, in the absence of evaporative cooling system, did not lead increasing the lettuce productivity to most cycles. Bigger lettuce leaf areas were found in periods with higher temperatures.
\end{abstract}

KEYWORDS: greenhouse, $\mathrm{CO}_{2}$, climatization.

\footnotetext{
${ }^{1}$ Prof. Dr., Universidade Estadual de Mato Grosso do Sul, Unidade Universitária de Aquidauana. Rodovia Aquidauana - CEPA, km 12, Caixa-Postal 25, Zona Rural, Aquidauana - MS, Fone: (0XX67) 3904.2905, Fax: (0XX67) 3904.2907, mestrine@uems.br

${ }^{2}$ Prof. Dr., FEAGRI/UNICAMP, Conselho Integrado de Tecnologia de Processos - CITP, FEAGRI/UNICAMP, Caixa Postal 6011, Campinas - SP, Fone: (0XX19) 3521.1037, Fax: (0XX19) 3521.1005, pamleal@ feagri.unicamp.br

Recebido pelo Conselho Editorial em: 29-9-2008

Aprovado pelo Conselho Editorial em: 24-8-2009 


\section{INTRODUÇÃO}

A alface é uma planta típica de países que apresentam temperaturas mais amenas. Sendo a principal hortaliça do consumidor brasileiro, pesquisas com melhoramento genético (FELTRIN et al., 2005) e cultivo em ambiente protegido (OTTO et al., 2001) possibilitaram seu cultivo em todas as épocas do ano, ampliando a oferta no mercado em épocas de escassez e possibilidade de obtenção de melhor preço (HOFFMANN et al., 1992; RODRIGUES et al., 1997).

Dentro do cultivo protegido, a hidroponia é um sistema de produção intensificada e muito adotada para a produção de alface, devido ao curto ciclo de produção (45-60 dias) e à fácil aceitação no mercado (LOPES et al., 2003), porém LUZ et al. (2006) relatam que muitos agricultores tradicionais sentem insegurança em mudar de sistema de produção.

Para o cultivo da alface em hidroponia, a técnica do filme nutriente (NFT) é a mais utilizada, porém pesquisas com substratos foram desenvolvidas por vários pesquisadores, como MEDEIROS et al. (2001) e ANDRIOLO et al. (2004), utilizando a fertirrigação, caracterizando que essa técnica simplifica o manejo nutricional e minimiza os gastos com energia elétrica; no entanto, a comercialização de plantas inteiras com as raízes é prejudicada, sendo minimizada com uso de substrato à base de areia.

$\mathrm{O}$ fornecimento de $\mathrm{CO}_{2}$, em períodos do dia em que os vegetais são mais ávidos pelo gás, propicia significativo aumento de produtividade, de precocidade e de qualidade do produto colhido. HANAN (1990) comenta que a aplicação de $\mathrm{CO}_{2}$ diretamente na planta, procedimentos usados pelos americanos e holandeses, é o sistema de distribuição de gás mais apropriado. Porém, GOMES et al. (2005), utilizando aplicação de $\mathrm{CO}_{2}$ via água de irrigação, em produção de alface em cultivo no solo, alcançaram aumento de produtividade de aproximadamente 20,5\%.

Pesquisas com acúmulo de nitrato em plantas de alface cultivada em hidroponia foram realizadas no Brasil por vários pesquisadores, como FERNANDES et al. (2002), BENINNI et al. (2002), TAKAHASHI et al. (2007) e MANTOVANI et al. (2005), em cultivo no solo, pelos pesquisadores KROHN et al. (2003), AQUINO et al. (2007), com teores de nutrientes na solução nutritiva e balanço nutricional por MOREIRA et al. (2001), BACKES at al. (2003), LOPES et al. (2003), BENINNI et al. (2003) e PEREIRA et al. (2005), e com estado nutricional a campo, com pesquisas desenvolvidas por MENEZES JÚNIOR et al. (2004) e AQUINO et al. (2007).

Poucos relatos são encontrados sobre a ambiência na produção hidropônica de alface. MATTOS et al. (2001) estudaram a temperatura nos canais de cultivo, porém não analisaram as condições microclimáticas do ambiente. PEZZOPANE et al. (2004), com o objetivo de caracterizar as alterações microclimáticas provocadas pelo uso de tela plástica na agricultura, desenvolveram um experimento com alface em Alegre - ES. Já DANTAS \& ESCOBEDO (1998) avaliaram e compararam a temperatura do ar, a evapotranspiração, o saldo de radiação solar e o rendimento da alface em condições experimentais, no verão e no inverno.

Estudos com ambiência em produção de alface no solo dentro de ambientes protegidos foram realizados por RADIN et al. (2004), BARROS JÚNIOR et al. (2004), BEZERRA NETO et al. (2005a, b), STRECK et al. (2007), AQUINO et al. (2007) e FIGUEIREDO et al. (2004). O uso de casas de vegetação com controle climático e incremento de $\mathrm{CO}_{2}$, ainda não estudado, faz-se necessário para avaliar a produção de alface em cultivo hidropônico.

Diante do exposto, este trabalho teve como objetivo estudar diferentes ambientes protegidos para a produção hidropônica de alface, utilizando injeção aérea de $\mathrm{CO}_{2}$ na atmosfera de produção e ambiente climatizado. 


\section{MATERIAL E MÉTODOS}

O experimento foi conduzido em casas de vegetação no campo experimental da Faculdade de Engenharia Agrícola (FEAGRI), da Universidade Estadual de Campinas (UNICAMP), Campinas - SP.

Utilizaram-se três casas de vegetação (ambientes), tipo "Capela", de estrutura metálica de aço, com dimensões de 6,5 $\mathrm{m}$ de largura, 11,0 $\mathrm{m}$ de comprimento, 3,0 $\mathrm{m}$ de pé-direito, coberta com filme de Polietileno de Baixa Densidade (PEBD) com $150 \mu \mathrm{m}$ de espessura, aditivado contra raios ultravioleta. O ambiente $\mathrm{A} 1$ consistiu em uma casa de vegetação sem a injeção de $\mathrm{CO}_{2}$ e sem resfriamento evaporativo do ar. O ambiente A2 foi uma casa de vegetação com injeção de $\mathrm{CO}_{2} \mathrm{e}$ sem resfriamento evaporativo do ar, e o ambiente $\mathrm{A} 3$, uma casa de vegetação com injeção de $\mathrm{CO}_{2} \mathrm{e}$ resfriamento evaporativo do ar.

Foram conduzidos cinco ciclos de cultivo $(\mathrm{C} 1, \mathrm{C} 2, \mathrm{C} 3, \mathrm{C} 4$ e C5) de alface hidropônica, cultivar "Vera", no sistema de bancadas tipo "A-frame" (Seção A), com a técnica da solução do filme nutriente (NFT), entre os meses de março de 2000 e janeiro de 2001 (Tabela 1).

TABELA 1. Datas do transplantio e colheita da alface nas diferentes estações do ano. Lettuce transplanting and harvest dates in different seasons of the year.

\begin{tabular}{cccc}
\hline Ciclos & Estação do Ano & Data de Transplantio & Data de Colheita \\
\hline C1 & Outono & $20-3-2000$ & $17-4-2000$ \\
C2 & Outono/inverno & $25-5-2000$ & $29-6-2000$ \\
C3 & Inverno & $13-7-2000$ & $21-8-2000$ \\
C4 & Inverno/primavera & $27-8-2000$ & $2-10-2000$ \\
C5 & Primavera/verão & $12-12-2000$ & $10-1-2001$ \\
\hline
\end{tabular}

Foram comparados os ambientes de cultivo, utilizando o delineamento inteiramente casualizado, em que a planta foi considerada a repetição. Para o ciclo de cultivo $\mathrm{C} 1$, utilizaram-se 48 repetições por ambiente; para os ciclos C2, C3 e C5, foram 64 repetições, e para o ciclo C4, foram 24 repetições.

A bancada inclinada, feita de estrutura metálica, possuía seção transversal em formato triangular, com dimensões de 4,0 m de comprimento por 1,40 m de largura basal e 1,37 m de altura. Cada bancada possuía 12 canais de polietileno (6 canais de cada lado), com dimensões de $0,10 \mathrm{~m}$ de diâmetro, distanciados $0,20 \mathrm{~m}$ verticalmente, com declividade de $3 \%$.

As mudas foram transplantadas para os canais de cultivo quando possuíam cerca de três folhas definitivas, com aproximadamente 30 dias de idade, sendo distribuídas nos canais com espaçamento de $0,25 \mathrm{~m}$ entre si, resultando em densidade de 15 plantas por canal.

A solução nutritiva utilizada foi a Kristalon Laranja, da Hydro Fertilizantee, cuja composição é apresentada na Tabela 2.

TABELA 2. Solução nutritiva utilizada nos experimentos, obtida comercialmente. Commercial nutritive solution used in the experiments.

\begin{tabular}{cccccc}
\hline \multicolumn{6}{c}{ Solução Nutritiva - Dosagem $\left(\mathrm{g} \mathrm{1.000^{-1 } \mathrm { L } ^ { - 1 } )}\right.$} \\
\hline Produto & $\begin{array}{c}\text { Kristalon } \\
\mathrm{N}-\mathrm{P}_{2} \mathrm{O}_{5}-\mathrm{K}_{2} \mathrm{O}-\mathrm{Mg} \\
(6-12-36-3)\end{array}$ & $\begin{array}{c}\text { Nitrato de } \\
\text { cálcio } \\
\text { (hydro) }\end{array}$ & $\begin{array}{c}\text { Tenso } \\
\text { coquetel }\end{array}$ & Tenso ferro & $\begin{array}{c}\text { C. E. (condutividade } \\
\text { elétrica) }\end{array}$ \\
\hline alface & 800 & 800 & 50 & 10 & 2,0 \\
\hline alface & 1.000 & Solução Nutritiva para Correção - Dosagem $\left(\mathrm{g} \mathrm{5}^{-1} \mathrm{~L}^{-1}\right)$ & \\
\hline
\end{tabular}

Obs: $250 \mathrm{~mL}$ de cada solução de correção para cada $0,1 \mathrm{~ms} \mathrm{~cm}^{-1} 1.000^{-1} \mathrm{~L}^{-1}$ 
Para o acionamento da bomba de injeção da solução nutritiva, utilizou-se de temporizador eletromecânico, da marca FLASH, responsável pela automação do tempo de circulação da solução e programado para operar intermitentemente a cada 10 minutos, das 6 às $11 \mathrm{~h}$ e das 14 às $19 \mathrm{~h}$. No intervalo das 11 às $14 \mathrm{~h}$, o sistema operou 20 minutos ligado e 10 desligado. Já para o período noturno, manteve-se acionado à 0 e $3 \mathrm{~h}$ por mais $10 \mathrm{~min}$. $\mathrm{O}$ sistema foi dimensionado para fornecer vazão de $1,5 \mathrm{~L} \mathrm{~min}^{-1}$ para cada canal de cultivo.

$\mathrm{O}$ dióxido de carbono $\left(\mathrm{CO}_{2}\right)$, injetado diretamente sobre as folhas das plantas, foi realizado nos períodos das 9 às $10 \mathrm{~h}$ e das 11 às $12 \mathrm{~h}$, nos ambientes $\mathrm{A} 2 \mathrm{e} \mathrm{A3}$, mantendo-se a concentração próxima de $800 \mathrm{ppm}$. No ambiente $\mathrm{A} 2$, em temperaturas não elevadas, o $\mathrm{CO}_{2}$ foi aplicado com as cortinas laterais fechadas.

$\mathrm{O}$ sistema de resfriamento evaporativo instalado no ambiente A3 foi composto pelo meio poroso de celulose (papelão ondulado, Munters®) com dimensões 6,5 x 0,54 x 0,10 m, e dois exaustores com diâmetro de $1,0 \mathrm{~m}$ e potência nominal de $1,0 \mathrm{~kW}$, que exauriam o ar interno.

Foram coletadas as temperaturas de bulbo seco (TBS) e de bulbo úmido (TBU), em graus Celsius, dos ambientes A2 e A3, utilizando psicrômetros aspirados, nos períodos de 22-3-2000 a 11-4-2000 (C1), de 1-6-2000 a 29-6-2000 (C2), de 14-7-2000 a 19-8-2000 (C3) e de 27-8-2000 a 2-10-2000 (C4). A partir dessas temperaturas, foram obtidas as umidades relativas em percentagem, utilizando o software "Psychrometric Function Demo". Devido a problemas ocorridos com os equipamentos, não foram registradas as temperaturas no quinto ciclo de cultivo (C5).

Mediu-se a radiação solar global interna e externa $\left(\mathrm{W} \mathrm{m}^{-2}\right)$ à casa de vegetação, a fotossinteticamente ativa "PAR" $\left(\mu \mathrm{mol} \mathrm{m} \mathrm{m}^{-2} \mathrm{~s}^{-1}\right)$ e a radiação ultravioleta (UV - em 254; 312 e $365 \mathrm{~nm})\left(\mathrm{W} \mathrm{m}^{-2}\right)$.

A radiação solar global e PAR foram registradas nos períodos de 23-3-2000 a 17-4-2000 (C1), de 27-5-2000 a 29-6-2000 (C2), de 14-7-2000 a 22-8-2000 (C3) e de 16-9-2000 a 2-10-2000 (C4). A radiação global foi registrada com piranômetros (Li-Cor L-200SZ, com precisão de 0,5\%), instalados apenas na casa de vegetação A3, a 0,30 m abaixo do filme de cobertura, e externamente sobre o plástico da cumeeira, e a PAR foi medida por meio de sensores quantum (Li-Cor Li 190SA com precisão de $0,5 \%)$ instalados em duas alturas $(0,70 \mathrm{~m}$ e $1,37 \mathrm{~m}$ do piso), nos três ambientes de cultivo.

A radiação ultravioleta, coletada nos períodos de 27-3-2000 a 17-4-2000 (C1), 26-5-2000 a 29-6-2000 (C2), 14-7-2000 a 20-8-2000 (C3), de 8-9-2000 a 2-10-2000 (C4) e de 12-1-2000 a 10-12002 (C5) foi medida por sensores Cole Parmer para três comprimentos de ondas de 254; 312 e $365 \mathrm{~nm}$ às $12 \mathrm{~h}$. Os sensores foram instalados à altura de $1,37 \mathrm{~m}$, apenas no ambiente $\mathrm{A} 3$, e externamente a 7,0 m do ambiente, devido à restrição de material. Os dados foram coletados por radiômetro portátil da Cole Parmer VLX 3W.

Avaliaram-se as massas frescas e secas em gramas, o número de folhas e a área foliar em milímetros quadrados. A área foliar foi determinada pelo método do peso do material em função de uma área conhecida (BENINCASA, 1988), e as massas, por meio de balança analítica. As plantas foram secas em estufa com circulação de ar a $60^{\circ} \mathrm{C}$, até atingirem massa constante.

Os dados foram submetidos à análise de variância, e as médias, ao teste de Tukey, a 5\% de probabilidade. As análises foram realizadas pelo programa computacional ESTAT (1994).

\section{RESULTADOS E DISCUSSÃO}

As médias de radiações fotossinteticamente ativas (PAR) nos períodos, para os três ambientes de cultivo, ficaram abaixo do ponto de saturação luminosa (Tabela 3). Contudo, nos períodos em que as plantas são mais ávidas pelo gás, entre 9 e $15 \mathrm{~h}$, as radiações fotossinteticamente ativas (PAR) atingiram e ultrapassaram o ponto de saturação. LARCHER (2004), citado por NIESING (2006), destaca que, para a alface, esse ponto fica compreendido entre 1.000 e $1.500 \mu \mathrm{mol} \mathrm{m}^{-2} \mathrm{~s}^{-1}$, e, 
segundo OTTO (1997), citado por SÁ \& REGHIN (2008), para a maioria das hortaliças, esse ponto situa-se ao redor de $1.200 \mu \mathrm{mol} \mathrm{m} \mathrm{s}^{-2}$.

Os verões na região de Campinas - SP são caracterizados pela abundância de radiação solar, onde CARON et al. (2003) destacam que o excesso de radiação pode ser prejudicial ao acúmulo de fitomassa e ao crescimento da alface, pois as folhas podem atingir o ponto de saturação de luz e diminuir a conversão de energia solar em energia química. ANDRIOLO (2000) explicita que a alta radiação, associada à alta temperatura, pode degradar os pigmentos de clorofila, reduzir a fotoassimilação de hidratos de carbono e aumentar a respiração da planta, consequentemente, desacelerando o crescimento e diminuindo o acúmulo de fitomassa.

Nos experimentos, verifica-se que, na época com temperatura mais elevada, obtiveram-se maiores valores de MFF (massa de matéria fresca foliar), como pode ser observado no ciclo $\mathrm{C} 1$ (Tabelas 3 e 4).

No ambiente A3, a umidade relativa foi maior que nos demais em todos os experimentos (Tabela 3), promovendo melhores condições fisiológicas para o crescimento e o desenvolvimento da planta. Nos ambientes A1 e A2, o processo convectivo do ar foi menor que no ambiente climatizado (COSTA et al., 2004; CUNHA \& ESCOBEDO, 2003), sendo mais evidente o efeito estufa, promovendo maior evapotranspiração em função de maior gasto de energia e, consequentemente, acarretando menor desenvolvimento às plantas.

No ciclo $\mathrm{C} 1$, o ambiente $\mathrm{A} 3$ promoveu UR 22,8\% maior que no ambiente A2; no ciclo $\mathrm{C} 2$, foi de $9,16 \%$; no ciclo C3, foi de 6,44\%, e no ciclo C4, foi de 6,39\% (Tabela 3). Observa-se que, com o passar do tempo, a eficiência psicrométrica do meio poroso foi diminuindo, provavelmente pelo desgaste do material (papelão ondulado, Munters ${ }^{\circledR}$ ) associado à época do ano.

Em experimentos desenvolvidos por JIE \& KONG (1998) com a cultura da alface, com temperaturas variando entre 25 e $39^{\circ} \mathrm{C}$, a maior taxa de fotossíntese ocorreu com radiações globais em torno de $240 \mathrm{Wm}^{-2}$. Pelos experimentos realizados em Campinas - SP, todas as épocas apresentam valores superiores, sendo o menor valor, no segundo ciclo de cultivo, de $262,77 \mathrm{Wm}^{-2} \mathrm{e}$ o maior valor, no quarto ciclo de cultivo, de 405,66 $\mathrm{Wm}^{-2}$ (Tabela 4). As radiações globais e PAR atingiram valores, no interior dos ambientes de cultivos, adequados para o desenvolvimento da alface.

Os valores médios de temperaturas de bulbo seco (Tabela 3) não afetaram o desenvolvimento das plantas, comparados com os valores descritos por CERMEÑO (1977), desta forma não sendo inibidoras da taxa de fotossíntese. No entanto, em períodos de maior incidência de radiação, entre 12 e $13 \mathrm{~h} 30$, as temperaturas chegaram a valores que poderiam diminuir essa taxa.

A relação entre as radiações globais interna e externa (GI/GE) foi superior aos valores encontrados em literatura, variando de $75,13 \%$, no ciclo C3, até $83,20 \%$, no ciclo C4 (Tabela 4), devido à localização do sensor, pois RICIERI \& ESCOBEDO (1996), para o PEBD de $150 \mu \mathrm{m}$, encontraram valores de 55,23\% na relação interna/externa em condições de céu coberto e de $65,34 \%$ em condições de céu limpo ou pequena difusividade. Ainda, ESCOBEDO et al. (1994) encontraram que a radiação solar global interna é aproximadamente $60 \%$ da radiação solar global externa. Mesmo recebendo menor quantidade de radiação global, o ambiente protegido é mais eficiente na conversão de radiação líquida disponível em matéria seca que o cultivo a campo (CUNHA et al., 2002). 
TABELA 3. Médias das temperaturas de bulbo seco (TBS), temperaturas de bulbo úmido (TBU), umidade relativa (UR), radiações fotossinteticamente ativa (PAR) em duas alturas 0,7 $\mathrm{m}$ e 1,37 m, nos ambientes para as diversas épocas de produção. Means of dry bulb temperatures (TBS), wet bulb temperatures (TBU), relative humidity (UR), and photosynthetically active radiation (PAR) at $0.7 \mathrm{~m}$ and $1.37 \mathrm{~m}$ heights, in environments for different periods of production.

\begin{tabular}{|c|c|c|c|c|c|c|}
\hline Ciclo de Cultivo & & $\mathrm{TBS}\left({ }^{\circ} \mathrm{C}\right)$ & TBU $\left({ }^{\circ} \mathrm{C}\right)$ & UR (\%) & $\operatorname{PAR}(0,7 \mathrm{~m})$ & $\operatorname{PAR}(1,37 \mathrm{~m})$ \\
\hline \multirow{4}{*}{$\mathrm{C} 1$} & A1 & - & - & - & $533,33 \mathrm{~B}$ & $637,17 \mathrm{~A}$ \\
\hline & $\mathrm{A} 2$ & $28,42 \mathrm{~A}$ & $23,02 \mathrm{~A}$ & 64,44 B & $537,50 \mathrm{~B}$ & $641,34 \mathrm{~A}$ \\
\hline & A3 & $24,13 \mathrm{~B}$ & $21,97 \mathrm{~B}$ & $83,48 \mathrm{~A}$ & $621,16 \mathrm{~A}$ & $643,41 \mathrm{~A}$ \\
\hline & C.V. $(\%)$ & 6,24 & 6,74 & 6,84 & 19,44 & 17,63 \\
\hline \multirow{4}{*}{$\mathrm{C} 2$} & A1 & - & - & - & $410,79 \mathrm{~A}$ & $437,40 \mathrm{~A}$ \\
\hline & $\mathrm{A} 2$ & $19,34 \mathrm{~A}$ & $16,70 \mathrm{~A}$ & $77,75 \mathrm{~B}$ & $400,21 \mathrm{~A}$ & $465,27 \mathrm{~A}$ \\
\hline & A3 & $18,18 \mathrm{~B}$ & $16,56 \mathrm{~A}$ & $85,59 \mathrm{~A}$ & $421,66 \mathrm{~A}$ & $374,15 \mathrm{~B}$ \\
\hline & C.V. $(\%)$ & 8,73 & 9,74 & 4,92 & 18,11 & 17,38 \\
\hline \multirow{4}{*}{ C3 } & A1 & - & - & - & $582,27 \mathrm{~A}$ & $476,96 \mathrm{~A}$ \\
\hline & $\mathrm{A} 2$ & $17,48 \mathrm{~A}$ & $14,99 \mathrm{~A}$ & $78,07 \mathrm{~B}$ & 461,07 B & 394,08 B \\
\hline & A3 & $16,71 \mathrm{~A}$ & $14,91 \mathrm{~A}$ & $83,44 \mathrm{~A}$ & $414,98 \mathrm{~B}$ & $462,38 \mathrm{~A}$ \\
\hline & C.V. $(\%)$ & 18,02 & 19,65 & 8,19 & 26,22 & 28,78 \\
\hline \multirow{4}{*}{$\mathrm{C} 4$} & A1 & - & - & - & $763,30 \mathrm{~A}$ & $577,04 \mathrm{~A}$ \\
\hline & $\mathrm{A} 2$ & $21,11 \mathrm{~A}$ & $18,46 \mathrm{~A}$ & 79,21 & $595,30 \mathrm{~B}$ & $582,19 \mathrm{~A}$ \\
\hline & A3 & $20,53 \mathrm{~A}$ & $18,67 \mathrm{~A}$ & 84,62 & $625,34 \mathrm{~B}$ & $640,60 \mathrm{~A}$ \\
\hline & C.V. $(\%)$ & 13,28 & 11,98 & 8,87 & 15,32 & 14,77 \\
\hline
\end{tabular}

* Médias seguidas de mesma letra, na coluna, não diferem entre si, pelo teste de Tukey, a 5\% de probabilidade.

A relação entre radiação ultravioleta interna e externa revelou que, para os comprimentos de onda de $312 \mathrm{~nm}$ e $365 \mathrm{~nm}$, os valores internos corresponderam a 39,03\% e 43,36\% dos valores externos, respectivamente, como média dos cinco períodos. Com o passar do tempo, observou-se que a relação interna/externa foi diminuindo, provavelmente devido ao acúmulo de sujeira no filme de polietileno (Tabela 4).

TABELA 4. Médias das radiações globais externa (EXT) e interna (IN), radiações ultravioletas (UV), relação entre as radiações violeta interna e externa (UVI/UVE) e entre as radiações globais interna e externa (GI, GE), para os diferentes ciclos de cultivo. Means of external (EXT) and internal (IN) global radiations, ultraviolet radiations (UV), relation between internal and external ultraviolet radiations (UVI/UVE), and relation between internal (GI) and external (GE) global radiations, for different cycles of cultivation.

\begin{tabular}{cccccccc}
\hline $\begin{array}{c}\text { Ciclos de } \\
\text { Cultivo }\end{array}$ & & $\begin{array}{c}\mathrm{UV}\left(\mathrm{W} \mathrm{m}^{-2}\right) \\
(312 \mathrm{~nm})\end{array}$ & $\begin{array}{c}\mathrm{UV}\left(\mathrm{W} \mathrm{m}^{-2}\right) \\
(365 \mathrm{~nm})\end{array}$ & $\begin{array}{c}\text { Global } \\
\left(\mathrm{W} \mathrm{m}^{-2}\right)\end{array}$ & $\begin{array}{c}312 \mathrm{UVI} / \mathrm{UVE} \\
(\%)\end{array}$ & $\begin{array}{c}365 \mathrm{UVI} / \mathrm{UVE} \\
(\%)\end{array}$ & $\begin{array}{c}\text { GI/GE } \\
(\%)\end{array}$ \\
\hline \multirow{2}{*}{ C1 } & EXT & 2,15 & 16,47 & 453,29 & 40,91 & 45,87 & 83,20 \\
& IN & 0,88 & 7,55 & 377,14 & & & \\
C2 & EXT & 0,88 & 9,45 & 332,85 & 41,91 & 44,14 & 78,95 \\
& IN & 0,37 & 4,17 & 262,77 & & & \\
C3 & EXT & 1,01 & 10,40 & 385,52 & 41,21 & 45,31 & 75,13 \\
& IN & 0,42 & 4,71 & 289,65 & & & \\
C4 4 & EXT & 2,35 & 17,27 & 533,79 & 33,87 & 38,13 & 75,99 \\
& IN & 0,80 & 6,58 & 405,66 & & & \\
C5 & EXT & 3,57 & 17,48 & & 37,27 & & \\
& IN & 1,33 & 6,67 & & & & \\
\hline
\end{tabular}


No primeiro ciclo de cultivo, a massa seca foliar (MSF) não apresentou diferenças significativas entre os ambientes de cultivo, no entanto a massa fresca foliar (MFF) e o número de folhas (NF) foram maiores no ambiente A3 em relação ao ambiente A1 (Tabela 5).

Em ambiente semelhante ao A1, STRECK et al. (2007), em cultivo no solo, encontraram valores semelhantes aos obtidos neste experimento, porém, para o número de folhas, obtiveram valores superiores, em Santa Maria - RS, com a cultivar "Regina", do grupo das folhas lisas. Nesse ciclo, a climatização do ambiente não promoveu plantas maiores, visto que o ambiente A2, mesmo não sendo climatizado, promoveu desempenho semelhante ao ambiente A3 para a MFF, pois ambos foram enriquecidos com $\mathrm{CO}_{2}$. Porém, o conjunto de climatização e enriquecimento com gás promoveu melhores condições para o desenvolvimento das plantas, constatado na comparação entre os ambientes A3 e A1.

A injeção de $\mathrm{CO}_{2}$ no ambiente $\mathrm{A} 2$ não foi suficiente para promover plantas maiores que o ambiente A1, nos ciclos C1, C3, C4 e C5, não obtendo plantas com maiores massas frescas e secas; contudo, no ciclo C2, obteve-se aumento de 19,1\% na massa fresca (Tabela 5). Em cultivo de alface no solo sob túneis baixos, GOMES et al. (2005), utilizando o $\mathrm{CO}_{2}$ via água de irrigação, conseguiram incrementos de $20 \%$ de produtividade em relação à não aplicação, enquanto FURLAN et al. (2001), em estufa, obtiveram aumentos de $27 \%$ em área foliar e matéria seca.

Em produção de tomates no solo em estufa, aplicando $\mathrm{CO}_{2}$ via água de irrigação, CARARO \& DUARTE (2002) obtiveram aumentos de 8,2\%, 13\% e 8,5\% de produtividade, massa fresca de frutos de tamanho pequeno e massa seca dos frutos, respectivamente, não verificando efeitos sobre o número de frutos e massa de frutos de tamanho médio.

O valor médio da MFF dos cinco ciclos de cultivo no ambiente A1 foi de 161,76 g (Tabela 5), enquanto, em estufa plástica não climatizada, em Santa Maria - RS, STRECK et al. (2007) observaram valores de 242,80 g para a cultivar "Regina", do grupo de folhas lisas em cultivo no solo, embora para diferente cultivar e sistema de cultivo, como média de sete experimentos realizados entre novembro de 1994 e julho de 1997.

O valor médio de MSF dos cinco ciclos foi de 10,99 g, no entanto, no segundo ciclo, obteve-se valor médio de 8,05 g, maior que o valor encontrado por RADIN et al. (2004) com as cultivares Regina (lisa), Verônica e Marisa (crespas) em cultivo no solo, em Eldorado do Sul - RS, que foi de $7,27 \mathrm{~g}$, no período de março a junho. Esses autores encontraram valores médios das três cultivares de 221,52 g para a MFF e de 20,6 para o NF, em produção no solo em estufa, maior que os valores obtidos neste trabalho, devido ao sistema de cultivo e a variedades diferentes, assim como em períodos distintos.

BEZERRA NETO et al. (2005b), avaliando o efeito de diferentes tipos de tela de sombreamento sobre o desenvolvimento da alface, cultivar Great Lakes (crespa), em cultivo no solo, obtiveram valores similares aos encontrados nos experimentos em Campinas - SP, tanto para a MFF quanto para o NF.

Em épocas mais frias do ano (ciclos C2, C3 e C4 - Tabela 3), o ambiente A3 promoveu maiores valores de MFF, MSF e NF (Tabela 5). No segundo ciclo, o ambiente A2 promoveu melhor desenvolvimento das plantas que o ambiente A1, tanto para a MFF quanto para a MSF; no entanto, o número de folhas não diferiu nos ciclos de cultivo $\mathrm{C} 3$ e $\mathrm{C} 4$, e tanto a MSF quanto o NF não diferiam nesses ambientes.

No ciclo de cultivo 5, o ambiente climatizado (A3) promoveu maior MFF que os demais, porém a MSF foi maior que no ambiente A2, que não diferiu do ambiente A1. Para o NF, o ambiente A3 foi maior que o A2, e esse maior que o A1 (Tabela 5). Esses resultados foram causados pelo fato de o ambiente 3 fornecer melhores condições climáticas ao desenvolvimento da alface, pelo fato de ter o sistema de resfriamento evaporativo atuando. 
A climatização (ambiente A3) promoveu melhores resultados de MFF nos ciclos C2, C3, C4 e C5 (Tabelas 3 e 5), evidenciando a importância da ambiência para a produção vegetal, corroborando explicitações de BURIOL et al. (1997) e SEGOVIA et al. (1997) em relação a modificações ambientais.

Em ambientes não climatizados, comparando-se os ambientes A1 e A2, a aplicação de $\mathrm{CO}_{2}$ (ambiente A2) não proporcionou incremento de massa na maioria das épocas, possivelmente não acarretando em aumento da taxa fotossintética.

TABELA 5. Massa de matéria fresca foliar (MMF), massa de matéria seca foliar (MMS) e número de folhas (NF) da cultura da alface, variedade "Vera", observados no dia da colheita. Leaf fresh mass (MMF), leaf dry mass (MMS), and number of leaves of lettuce, variety "Vera", observed at harvest days.

\begin{tabular}{|c|c|c|c|}
\hline \multicolumn{4}{|c|}{ Ciclo de cultivo C1 - 20-3-2000 à 17-4-2000 } \\
\hline & MFF $(g)$ & MSF (g) & NF \\
\hline A1 & $225,55 \mathrm{~B}$ & $15,32 \mathrm{~A}$ & $14,71 \mathrm{~B}$ \\
\hline A 2 & $241,25 \mathrm{AB}$ & $15,28 \mathrm{~A}$ & $15,12 \mathrm{~A} \mathrm{~B}$ \\
\hline A3 & $264,73 \mathrm{~A}$ & $15,95 \mathrm{~A}$ & $15,89 \mathrm{~A}$ \\
\hline C.V. $(\%)$ & 23,05 & 23,22 & 13,99 \\
\hline \multicolumn{4}{|c|}{ Ciclo de cultivo C2 - 25-5-2000 à 29-6-2000 } \\
\hline A1 & $118,48 \mathrm{C}$ & $8,05 \mathrm{C}$ & $14,12 \mathrm{~B}$ \\
\hline $\mathrm{A} 2$ & $141,12 \mathrm{~B}$ & $8,94 \mathrm{~B}$ & $14,78 \mathrm{~B}$ \\
\hline A3 & $183,41 \mathrm{~A}$ & $11,05 \mathrm{~A}$ & $16,95 \mathrm{~A}$ \\
\hline C.V. $(\%)$ & 20,95 & 21,11 & 13,58 \\
\hline \multicolumn{4}{|c|}{ Ciclo de cultivo C3 - 13-7-2000 à 21-8-2000 } \\
\hline A1 & $126,62 \mathrm{~B}$ & $8,60 \mathrm{~B}$ & $13,16 \mathrm{~B}$ \\
\hline $\mathrm{A} 2$ & $138,56 \mathrm{~B}$ & $8,77 \mathrm{~B}$ & $13,97 \mathrm{~B}$ \\
\hline A3 & $177,87 \mathrm{~A}$ & $10,71 \mathrm{~A}$ & $16,08 \mathrm{~A}$ \\
\hline C.V. $(\%)$ & 28,47 & 28,26 & 17,28 \\
\hline \multicolumn{4}{|c|}{ Ciclo de cultivo C4 - 27-8-2000 à 2-10-2000 } \\
\hline A1 & $102,92 \mathrm{~B}$ & $6,99 \mathrm{~B}$ & $11,50 \mathrm{~B}$ \\
\hline $\mathrm{A} 2$ & $109,98 \mathrm{~B}$ & $6,96 \mathrm{~B}$ & $11,33 \mathrm{~B}$ \\
\hline A3 & $174,39 \mathrm{~A}$ & $10,50 \mathrm{~A}$ & $15,96 \mathrm{~A}$ \\
\hline C.V. $(\%)$ & 26,96 & 26,48 & 26,34 \\
\hline \multicolumn{4}{|c|}{ Ciclo de cultivo C5 - 12-12-2000 à 10-1-2001 } \\
\hline A1 & $235,22 \mathrm{~B}$ & $15,97 \mathrm{AB}$ & $13,77 \mathrm{C}$ \\
\hline $\mathrm{A} 2$ & $241,41 \mathrm{~B}$ & $15,29 \mathrm{~B}$ & $15,41 \mathrm{~B}$ \\
\hline A3 & $282,16 \mathrm{~A}$ & $16,99 \mathrm{~A}$ & $18,20 \mathrm{~A}$ \\
\hline C.V. $(\%)$ & 24,50 & 24,72 & 16,41 \\
\hline
\end{tabular}

* Médias seguidas de mesma letra, na coluna, não diferem entre si, pelo teste de Tukey, a 5\% de probabilidade.

\section{CONCLUSÕES}

O ambiente climatizado com incremento de dióxido de carbono promoveu melhor desenvolvimento das plantas, com maior número de folhas.

Em ambientes não climatizados, o incremento de $\mathrm{CO}_{2}$ não resultou em aumento de produtividade da alface para a maioria dos ciclos. de folhas.

Em épocas de temperaturas mais elevadas, obtiveram-se plantas maiores, com maior número

As relações entre as radiações globais interna e externa e entre as radiações ultravioleta interna e externa diminuíram com o passar do tempo, época de cultivo e devido ao acúmulo de 
impurezas na cobertura da casa de vegetação, onde, no início de produção, a radiação global interna foi aproximadamente $83,20 \%$ da radiação solar global.

\section{AGRADECIMENTOS}

À FAPESP (Proc. 98/10478-3), pelo financiamento concedido à pesquisa, e à CAPES, pela bolsa de Mestrado.

\section{REFERÊNCIAS}

ANDRIOLO, J.L. Fisiologia da produção de hortaliças em ambiente protegido. Horticultura Brasileira, Brasília, v.18, p.26-33, 2000. Suplemento.

ANDRIOLO, J.L.; LUZ, G.L.; GIRALDI, C.; GODOI, R.S.; BARROS, G.T. Cultivo hidropônico da alface empregando substratos: uma alternativa a NFT? Horticultura Brasileira, Brasília, v.22, n.4, p.794-798, 2004.

AQUINO, L.A.; PUIATTI, M.; ABAURRE, M.E.O.; CECON, P.R.; PEREIRA, P.R.G.; PEREIRA, F.H.F.; CASTRO, M.R.S. Produção de biomassa, acúmulo de nitrato, teores e exportação de macronutrientes da alface sob sombreamento. Horticultura Brasileira, Brasília, v.25, p.381-386, 2007.

BACKES, F.A.A.L.; SANTOS, O.; SCHMIDT, D.; NOGUEIRA FILHO, H.; MANFRON, P.A.; CASAROLI, D. Reposição de nutrientes durante três cultivos de alface em hidroponia. Horticultura Brasileira, Brasília, v.21, n.4, p.590-596, 2003.

BARROS JÚNIOR, A.P.; GRANGEIRO, L.C.; BEZERRA NETO, F.; NEGREIROS, M.Z.; SOUZA, J.O.; AZEVEDO, P.E.; MEDEIROS, D.C. Cultivo da alface em túneis baixos de agrotêxtil. Horticultura Brasileira, Brasília, v.22, n.4, p.801-803, 2004.

BENINCASA, M.M.P. Análise de crescimento de plantas. Jaboticabal: FUNEP, 1988. 42 p.

BENINNI, E.R.Y.; TAKAHASHI, H.W.; NEVES, C.S.V.J. Manejo do cálcio em alface de cultivo hidropônico. Horticultura Brasileira, Brasília, v.21, n.4, p.605-610, 2003.

BENINNI, E.R.Y.; TAKAHASHI, H.W.; NEVES, C.S.V.J.; FONSECA, I.C.B. Teor de nitrato em alface cultivada em sistemas hidropônico e convencional. Horticultura Brasileira, Brasília, v.20, n.2, p.183-186, 2002.

BEZERRA NETO, F.; ROCHA, R.H.C.; ROCHA, R.C.C.; NEGREIROS, M.Z.; LEITÃO, M.M. V.B.R.; NUNES, G.H.S.; ESPÍNOLA SOBRINHO, J.; QUEIROGA, R. C.L.F. Sombreamento para produção de mudas de alface em alta temperatura e ampla luminosidade. Horticultura Brasileira, Brasília, v.23, n.1, p.133-137, 2005a.

BEZERRA NETO, F.; ROCHA, R.C.C.; NEGREIROS, M.Z.; ROCHA, R.H.C.; QUEIROGA, R.C.F. Produtividade de alface em função de condições de sombreamento e temperatura e luminosidade elevadas. Horticultura Brasileira, Brasília, v.23, n.2, p.189-192, 2005b.

BURIOL, G.A.; LUFT, S.V.L.; HELDWEIN, A.B.; STRECK, N.A.; SCHNEIDER, F.M. Efeito da ventilação sobre a temperatura e umidade do ar em túneis baixos de polietileno transparente e o crescimento da alface. Revista Brasileira de Agrometeorologia, Santa Maria, v.5, n.1, p.17-24, 1997.

CARARO, D.C.; DUARTE, S.N. Injeção de $\mathrm{CO}_{2}$ e lâminas de irrigação em tomateiro sob estufa. Horticultura Brasileira, Brasília v.20, n.3, p.232-437, 2002.

CARON, B.O.; MEDEIROS, S.L.P.; MANFRON, P.A.; SCHMIDT, D.; BIANCHI, C.; POMMER, S.F. Eficiência de conversão da radiação fotossinteticamente ativa interceptada em fitomassa de alface. Revista Brasileira de Agrometeorologia, Santa Maria, v.11, n.2, p.261-268, 2003.

CERMEÑO, Z.S. Cultivo de plantas hortícolas em estufas. Lisboa: Litexa, 1977. 355 p. 
COSTA, E.; LEAL, P.M.; CARMO JÚNIOR, R.R. Modelo de simulação da temperatura e umidade relativa do ar no interior da estufa plástica. Engenharia Agrícola, Jaboticabal, v.24, n.1, p.57-67, 2004.

CUNHA, A.R.; ESCOBEDO, J.F. Alterações micrometeorológicas causadas pela estufa plástica e seus efeitos no crescimento e produção da cultura de pimentão. Revista Brasileira de Agrometeorologia, Santa Maria, v.11, n.1, p.15-27, 2003.

CUNHA, A.R.; ESCOBEDO, J.F.; KLOSOWSKI, É.S. Estimativa do fluxo de calor latente pelo balanço de energia em cultivo protegido de pimentão. Pesquisa Agropecuária Brasileira, Brasília, v.37, n.6, p.735-743, 2002.

DANTAS, R.T.; ESCOBEDO, J.F. Parâmetros agrometeorológicos e rendimento da alface (Lactuca sativa L.) em ambientes natural e protegido. Energia na Agricultura, Botucatu, v.13, n.3, p.10-15, 1998.

ESCOBEDO, J.F.; SOUZA, J.L.; RICIERI, R.P. Relações entre a radiação solar global e o saldo de radiação em uma estufa de polietileno. In: CONGRESSO BRASILEIRO DE METEOROLOGIA, 8., 1994, Belo Horizonte. Anais... Belo Horizonte: Sociedade Brasileira de Meteorologia, 1994. p.456-9.

ESTAT. Versão 2.0. Jaboticabal: Departamento de Ciências Exatas, FCAV, UNESP, 1994.

FELTRIM, A.L.; CECÍLIO FILHO, A.B.; BRANCO, R.B.F.; BARBOSA, J.C.; SALATIEL, L.T. Produção de alface-americana em solo e em hidroponia, no inverno e verão, em Jaboticabal - SP. Revista Brasileira de Engenharia Agrícola e Ambiental, Campina Grande, v.9, n.4, p.505-509, 2005.

FERNANDES, A.A.; MARTINEZ, H.E.P.; PEREIRA, P.R.G.; FONSECA, M.C.M. Produtividade, acúmulo de nitrato e estado nutricional de cultivares de alface, em hidroponia, em função de fontes de nutrientes. Horticultura Brasileira, Brasília, v.20, n.2, p.195-200, 2002.

FIGUEIREDO, E.B.; MALHEIROS, E.B.; BRAZ, L.T. Interação genótipo x ambiente em cultivares de alface na região de Jaboticabal. Horticultura Brasileira, Brasília, v.22, n.1, p.66-71, 2004.

FURLAN, R.A.; ALVES, D.R.B.; FOLEGATTI, M.V.; BOTREL, T.A.; MINAMI, K. Dióxido de carbono aplicado via água de irrigação na cultura de alface. Horticultura Brasileira, Brasília, v.19, n.1, p.25-29, 2001.

GOMES, T.M.; BOTREL, T.A.; MODOLO, V.A.; OLIVEIRA, R.F. Aplicação de $\mathrm{CO}_{2}$ via água de irrigação na cultura da alface. Horticultura Brasileira, Brasília, v.23, n.2, p.316-319, 2005.

HANAN, J.J. The influence of greenhouse on internal climate with special reference to Mediterranean regions. Protected Cultivation of vegetables. Acta Horticulturae, Belgium, v.287, n.1, p.23-34, 1990.

HOFFMANN, R.; ENGLER, J.J.C.; SERRANO, O. Administração da empresa agrícola. 7.ed. São Paulo: Pioneira. 1992. 325 p.

JIE, H.; KONG, L.S. Growth and photosynthetic responses of three aeroponically grown Lettuce cultivars (Lactuca sativa L.) to different rootzone temperatures and growth irradiances under tropical aerial conditions. Journal of Horticultural Science and Biotechnology, United Kingdom, v.73, n.2, p.173-180, 1998.

KROHN, N.G.; MISSIO, R.F.; ORTOLAN, M.L.; BURIN, A.; STEINMACHER, D.A.; LOPES, M.C. Teores de nitrato em folhas de alface em função do horário de coleta e do tipo de folha amostrada. Horticultura Brasileira, Brasília, v.21, n.2, p.216-219, 2003. 
LOPES, M.C.; FREIER, M.; MATTE, J.C.; GÄRTNER, M.; FRANZENER, G.; NOGAROLLI, E.L.; SEVIGNANI, A. Acúmulo de nutrientes por cultivares de alface em cultivo hidropônico no inverno. Horticultura Brasileira, Brasília, v.21, n.2, p.211-215, 2003.

LUZ, J.M.Q.; GUIMARÃES, S.T.M.R.; KORNDÖRFER, G.H. Produção hidropônica de alface em solução nutritiva com e sem silício. Horticultura Brasileira, Brasília, v.24, p.295-300, 2006.

MANTOVANI, J.R.; FERREIRA, M.E.; CRUZ, M.C.P. Produção de alface e acúmulo de nitrato em função da adubação nitrogenada. Horticultura Brasileira, Brasília, v.23, n.3, p.758-762, 2005.

MATTOS, K.M.C.; ANGELOCCI, L.R.; FURLANI, P.R.; NOGUEIRA, M.C.S. Temperatura do ar no interior do canal de cultivo e crescimento da alface em função do material de cobertura da mesa de cultivo Hidropônico - NFT. Bragantia, Campinas, v.60, n.3, p.253-26, 2001.

MEDEIROS, L.A.M.; MANFRON, P.A.; MEDEIROS, S.L.P.; BONNECARRÈRE, R.G.

Crescimento e desenvolvimento da alface (Lactuca sativa L.) conduzida em estufa plástica com fertirrigação em substratos. Ciência Rural, Santa Maria, v.31, n.2, p.199-204, 2001

MENEZES JÚNIOR, F.O.G.; MARTINS, S.R.; FERNANDES, H.S. Crescimento e avaliação nutricional da alface cultivada em "NFT" com soluções nutritivas de origem química e orgânica. Horticultura Brasileira, Brasília, v.22, n.3, p.632-637, 2004.

MOREIRA, M.A.; FONTES, P.C.R.; CAMARGOS, M.I. Interação zinco e fósforo em solução nutritiva influenciando o crescimento e a produtividade da alface. Pesquisa Agropecuária Brasileira, Brasília, v.36, n.6, p.903-909, 2001

NIESING, P.C. Cultivo protegido de cultivares de alface-americana no inverno e primavera em Ponta Grossa - PR. 2006. 64 f. Dissertação (Mestrado em Agronomia) - Setor de Ciências Agrárias e de Tecnologia, Universidade Estadual de Ponta Grossa, Ponta Grossa, 2006.

OTTO, R.F. Cubiertas de agrotextil en especies hortícolas: balances térmicos, evapotranspiracion y respuestas productivas. 1997. 157 f. Tesis (Doctoral) - Universidad de Córdoba, Córdoba, 1997.

OTTO, R.F.; REGHIN, M.Y.; SÁ, G.D. Utilização do 'não tecido' de polipropileno como proteção da cultura de alface durante o inverno de Ponta Grossa - PR. Horticultura Brasileira, Brasília, v.19, n.1, p.49-52, 2001.

PEREIRA, C.; JUNQUEIRA, A.M.R.; OLIVEIRA, S.A. Balanço nutricional e incidência de queima de bordos em alface produzida em sistema hidropônico - NFT. Horticultura Brasileira, Brasília, v.23, n.3, p.810-814, 2005.

PEZZOPANE, J.E.M.; OLIVEIRA, P.C. de; REIS, E.F. dos; LIMA, J.S. de S. Alterações microclimáticas causadas pelo uso de tela plástica. Engenharia Agrícola, Jaboticabal, v.24, n.1, p.915, 2004.

RADIN, B.; REISSER JÚNIOR, C.; MATZENAUER, R.; BERGAMASCHI, H. Crescimento de cultivares de alface conduzidas em estufa e a campo. Horticultura Brasileira, Brasília, v.22, n.2, p.178-181, 2004.

RICIERI, R.P.; ESCOBEDO, J.F. Radiação solar global e difusa em estufas túneis com cobertura de polietileno. Energia na Agricultura, Botucatu, v.11, n.1, p.5-37, 1996.

RODRIGUES, A.B.; MARTINS, M.I.E.G.; ARAÚJO, J.C.C. Avaliação econômica da produção de alface em estufa. Informações Econômicas, São Paulo, v.27, n.1, p.27-33, 1997.

SÁ, G.D.; REGHIN, M.Y. Desempenho de duas cultivares de chicória em três ambientes de cultivo. Ciência e Agrotecnologia, Lavras, v.32, n.2, p.378-384, 2008.

SEGOVIA, J.F.O.; ANDRIOLO, J.L.; BURIOL, G.A.; SCHNEIDER, F.M. Comparação do crescimento e desenvolvimento da alface (Lactuca sativa L.) no interior e no exterior de estufas de polietileno em Santa Maria - RS. Ciência Rural, Santa Maria, v.27, n.1, p.37-41, 1997. 
STRECK, L.; SCHNEIDER, F.M.; BURIOL, G.A.; LUZZA, J.; SANDRI, M.A. Sistema de produção de alface em ambiente parcialmente modificado por túneis baixos. Ciência Rural, Santa Maria, v.37, n.3, p.667-675, 2007.

TAKAHASHI, H.W.; HIDALGO, P.C.; FADELLI, L.; CUNHA, M.E.T. Composição e manejo da solução nutritiva visando à diminuição do teor de nitrato nas folhas de alface hidropônica.

Horticultura Brasileira, Brasília, v.25, n.1, p.6-9, 2007. 